\title{
TEACHING METHODS IN MBA AND LIFELONG LEARNING PROGRAMMES FOR MANAGERS
}

\section{Eva Jarošová ${ }^{\bowtie}$, Hana Lorencová ${ }^{2}$, Kateřina Půbalová ${ }^{2}$, Lukáš Šedivýz}

${ }^{1 \bowtie}$ Department of Managerial Psychology and Sociology, Faculty of Business Administration, University of Economics, Prague, nám. Winstona Churchilla 4, Praha 3, 130 67, Czech Republic, eva.jarosova2@vse.cz

${ }^{2}$ Department of Managerial Psychology and Sociology, Faculty of Business Administration, University of Economics, Prague, Czech Republic

${ }^{3}$ Department of Semiconductors and Semiconductor Optoelectronics, Institute of Physics, Charles University, Prague, Czech Republic

\section{Highlights}

- Unique survey among managers on the teaching methods used during MBA and Lifelong Learning Programmes (LLP)

- Measuring the usefulness of selected teaching methods for participants' conceptual understanding of leadership, leadership skills development, and personal growth

\section{Abstract}

Teaching methods in MBA and Lifelong Learning Programmes (LLP) for managers should be topically relevant in terms of content as well as the teaching methods used. In terms of the content, the integral part of MBA and Lifelong Learning Programmes for managers should be the development of participants' leadership competencies and their understanding of current leadership concepts. The teaching methods in educational programmes for managers as adult learners should correspond to the strategy of learnercentred teaching that focuses on the participants' learning process and their active involvement in class. The focus on the participants' learning process also raises questions about whether the programme's participants perceive the teaching methods used as useful and relevant for their development as leaders. The paper presents the results of the analysis of the responses to these questions in a sample of 54 Czech participants in the MBA programme and of lifelong learning programmes at the University of Economics, Prague. The data was acquired based on written or electronically submitted questionnaires. The data was analysed in relation to the usefulness of the teaching methods for understanding the concepts of leadership, leadership skills development as well as respondents' personal growth. The results show that the respondents most valued the methods that enabled them to get feedback, activated them throughout the programme and got them involved in discussions with others in class. Implications for managerial education practices are discussed.

\section{Keywords}

Leadership, learner-centred teaching, managerial education, teaching methods

Jarošová E., Lorencová H., Půbalová K., Šedivý L. (2017) “Teaching Methods in MBA and Lifelong Learning Programmes for Managers", Journal on Efficiency and Responsibility in Education and Science, Vol. 10, No. 3, pp. 86-92, online ISSN 1803-1617, printed ISSN 2336-2375, doi: 10.7160/eriesj.2017.100304.

\section{Introduction}

Managerial education and development takes place in formal programmes outside of the workplace as well as in informal training opportunities at work in a managerial position. Managers learn or adopt knowledge and skills that will allow them to carry out or improve their current or future professional roles (Sadler-Smith, 2006: 2). Studying for an MBA or in shortterm lifelong learning programmes are examples of formal programmes. The teaching methods used in them have gone through certain changes that can be described briefly as a shift from teacher-centred to learner-centred teaching.

Learner-centred teaching focuses on the participants' learning process. The teacher's role is not to transmit knowledge from the instructor to the students, but to facilitate their learning. The emphasis is on using and communicating knowledge effectively to address enduring and emerging issues and problems in real-life contexts (Huba and Freed, 2000). This "facilitative" style of teaching creates an inspiring and psychologically safe environment in which learners explore the subject by themselves as well as in peer groups. This teaching style works best when learners already have prior knowledge of the subject as well as experience or existing skills (Beevers and Rea, 2010).

It's very important for managerial education to respect its participants' actual learning needs and provide them with learning opportunities that are clearly linked to their everyday work. Managers approach education (similarly to adult learners) in a more utilitarian way than students or undergraduate students. Teaching methods in managerial education should motivate participants to engage continuously in the learning process. They should also enable participants of the education programme to build upon their experience, reflect on it, and add theoretical background that will make them more effective in their managerial work and help them to develop their selfawareness (Waddock and Lozano, 2013).

Managerial education also focuses on developing leadership competencies and skills. Although management and leadership are different in many ways (Kotter, 1996), they also overlap. At the level of the individual, this means that managers are expected to provide leadership and to acquire leadership knowledge, skills, and abilities, i.e. competencies (Day and Dragoni, 2015). For organizations, competent leaders are one of the basic requirements of their survival in the turbulent conditions of the modern world. The topic of leadership is thus an integral part of managerial education, because organisations cannot afford to have managers without leadership competencies.

People in managerial positions tend to evaluate their leadership behaviour higher than when it's judged by their subordinates (see, for example, Mehdinezhad and Sardarzahi, 2015). Teaching methods in managerial education should thus provide participating managers with the opportunity not only to understand theoretical concepts and to develop specific leadership skills, but also to self-reflect and gain valuable feedback on their leadership behaviours. 
Leadership could be defined as a "process whereby an individual influences a group of individuals to achieve a common goal" (Northouse, 2016: 6). For a leader to influence others, he or she must be a person that others are willing to follow. According to Hogan and Kaiser (2005), people seek four essential characteristics in leaders: integrity, judgement, competence, and vision. The most important of these characteristics is integrity, which creates trust between the leader and his or her followers. According to the above-mentioned authors trust in one's superior predicts the entire range of desirable organisational outcomes: productivity, job satisfaction, and organisational commitment (Hogan and Kaiser, 2005). Integrity must be understood as a personal trait of being honest with oneself and others; it's aligned with one's values system and ethic beliefs. It's also connected to the ability of self-insight, of being open to feedback and willing to perceive the wider context and consequences of one's behaviour.

In terms of the managerial education programmes, there are demands for them to contain ideas for the personal development of their participants that could contribute to a greater extent to their personal integrity and thus trustworthiness as leaders. According to Hall (2004: 154) ,leader development is largely personal development" while a crucial aspect of personal development is self-awareness (Hall, 2004). Managerial learning thus should include not only the acquisition of relevant knowledge and skills, but also opportunities for increasing selfawareness.

Which of the teaching methods can be used to achieve this? One appropriate framework is the so-called whole person learning, which is an extended model of experiential learning (also known as Kolb's learning cycle) that has gradually been advanced since the 1980s. Whole person learning exposes participants in learning programmes to "both direct and vicarious modes of participation” and enables them ,cognitively, emotionally, and behaviourally to process knowledge, skills, and/or attitudes in a high intensity learning situation characterized by a high level of active involvement" (Hoover et al. 2010: 195).

Managerial education programmes, such as the MBA or short-term LLP, should therefore use a wide spectrum of teaching methods that facilitate the cognitive processing and understanding of leadership concepts as well as the adoption of leadership skills, and encourage self-development. This is in accordance with Conger (1992), who suggested four primary approaches to leadership development: conceptual understanding, skills building, personal growth, and feedback. This situation, such as it is described, raises questions on the methods used in management programmes for leaders' development and their frequency, relevance, and effectiveness. With regard to learner-centred focus, an important criterion of the evaluation of the teaching methods applied is the managerial education programmes' participants' own perception and assessment of those methods. These are important questions to ask in all managerial education programmes. In our study, we focused on managerial programmes realised by the International School of Business and Management (ISBM) of the University of Economics in Prague.

Therefore, the objective of the presented study was the analysis of the frequency and perceived usefulness of the teaching methods in the examined managerial programmes. The research questions were as follows: how frequently are the particular methods used in MBA programmes and short-term lifelong learning programmes (LLP)? What specific teaching methods did the participants in managerial education programmes, MBA programmes, and short-term lifelong learning programmes (LLP) consider useful for the conceptual understanding of leadership, leadership skills development, and personal development? How does the frequency of the methods used differ from their perceived usefulness for different purposes (namely the conceptual understanding of leadership, leadership skills development, and personal growth)? ${ }^{1}$

\section{Materials and Methods}

The data used for this paper was collected within the Norway funds project on the basis of a questionnaire survey that took place in the spring of 2015. The respondents were participants of managerial education programmes (MBA and lifelong learning programmes) from both partner institutes involved in the project, i.e. the University of Economics, Prague (VŠE, CZ) and Sogn og Fjordane University College (NO). The collected results for both countries were first published at the EGPA Annual Conference in August 2015 (Bukve et al., 2015). For the purposes of this paper, only data for the Czech Republic was used, which were the answers of the participants of the lifelong learning and MBA programmes that are taught at the International School of Business and Management (ISBM) of the Faculty of Business Administration VŠE. LLP programmes are one-offs and tailored to their participants' needs (as part of company training) and are one-semester long. The length of study in the MBA programme is 2.5 years (a total of 90 ECTS). In order to approach the above-mentioned questions, we designed a survey. Prior to developing the survey, we identified the 14 different teaching methods used in the programmes under study. The list of methods is adapted from Daniel Jenkins's list of instructional strategies (Jenkins, 2013), taking into account the methods with relevance to the programmes under study. An appendix containing the definitions of all the relevant teaching methods was attached to the questionnaire to prevent misunderstandings. The methods were described as follows:

- Case study: participants examine written or oral stories highlighting a case of effective or ineffective leadership or managing organisation.

- Large group discussion: instructor facilitates sustained discussion, asks or answers questions concerning the given topic with the entire class.

- Interactive lectures: instructor presents information in 10-20-minute time blocks with periods of structured interaction and discussion between mini-lectures.

- Lectures: participants listen to instructor presentations lasting most of the class session.

- Reflective/experience writing: participants develop written reflections and analyses on their experiences (usually experience in the role of leader/ manager).

- Self-assessment questionnaires: participants complete questionnaires or other diagnostic instruments designed to enhance their self-awareness in variety of areas (e.g. communication style, personality type, leadership style, etc.).

- Role-playing: participants engage in activities where they act out roles according to a given scenario. The goal is to evolve the desired (managerial) skills.

- Small group discussions: participants take part in small group discussions on the topic of leadership or

$1 \quad$ This article is the expanded version of an article published at the ERIE 2016 conference (13th International Conference on Efficiency and Responsibility in Education 2016) held at the Czech University of Life Sciences in Prague. The data was then analysed further. It contains other results that weren't part of the conference article in 2016. 
other aspects of managerial practice, sharing their own experiences.

- Feedback: participants receive feedback from the lecturer or their colleagues.

- Simulations, model situations: participants engage in activities simulating complex problems and requiring final decision-making (e.g. simulations of team decision making, meetings, etc.)

- Research projects: participants actively research a leadership theory or other topic and present findings in writing.

- Short written exercises: participants complete given sentences, answer written questions, etc. designed to enhance understanding of the course content.

- Exams, knowledge tests: participants complete tests or exams designed to appraise their level of understanding of the given topic.

- Oral presentations: based on individual or team preparation, participants present knowledge of the area of management or leadership in oral presentations to other participants.

Respondents were asked about how often the teaching methods were used in their programme, and how useful they found the methods for different purposes. In this paper, we analysed the teaching methods' usefulness for the conceptual understanding of leadership, the development of leadership skills and personal growth. These three purposes are based on Conger's primary approaches to leadership development (Conger, 1992), with the exception of feedback, which is included in the list of teaching methods (see above). The students filled out the questionnaires online (based on a link sent to them) or on paper, always after completing a course or a part of the programme devoted to leadership.

The overall number of completed questionnaires for the $\mathrm{CZ}$ was 54 (the response rate was $55 \%$ ), of those $60.7 \%$ were women and $30.5 \%$ men. Most of the respondents were participants in lifelong learning programmes $(66.6 \%)$, others were students of the MBA programme (33.3\%).

Descriptive statistical characteristics were calculated in the statistical analysis of the collected surveys (mean, standard deviation, minimal and maximal values. Analysis was performed in statistical language $\mathrm{R}$ ( $\mathrm{R}$ Core Team, version 2017). The differences between teaching methods were analysed by using within-subject ANOVA.

\section{Results}

The respondents were asked to report the frequency of the usage of each teaching method from the prepared list using a rating scale of 1 to $4(1=$ never, $2=$ rarely, $3=$ sometimes, $4=$ often $)$. The results are presented in Table 1.

The respondents found discussions in small groups (3.50), larger groups (3.35), and feedback (3.35) as the methods most frequently used in their type of training.
The frequency of the various methods used in teaching

\begin{tabular}{|l|c|c|}
\hline \multicolumn{1}{|c|}{ Method } & Mean & SD \\
\hline Small Group Discussion & 3.50 & 0.86 \\
\hline Large Group Discussion & 3.35 & 0.91 \\
\hline Feedback & 3.35 & 0.87 \\
\hline Interactive Lectures & 3.26 & 0.96 \\
\hline Simulations, Model Situations & 3.22 & 0.88 \\
\hline Case studies & 3.19 & 0.97 \\
\hline Lectures & 3.07 & 0.99 \\
\hline Role-Playing & 3.02 & 0.98 \\
\hline Self-Assessment Questionnaires & 2.98 & 0.94 \\
\hline Oral Presentation & 2.69 & 1.04 \\
\hline Reflective methods & 2.46 & 1.00 \\
\hline Exams, Knowledge Test & 2.43 & 1.34 \\
\hline Short Written Exercise & 2.30 & 0.96 \\
\hline Research Projects & 1.74 & 0.94 \\
\hline
\end{tabular}

Table 1: Frequency of the methods used in teaching, 2015 (source: own research)

The results of the survey of the frequency of the various types of teaching methods used in MBA and lifelong learning programmes at the University of Economics, Prague can be considered very encouraging (see Tab. 1). It can be said that traditional teaching methods such as lectures (3.07), exams, knowledge tests (2.43), and short written exercises (2.30) are techniques that are less frequently used compared to learner-centred interactive methods such as small/large group discussion (3.50/3.35), case studies (3.19), and interactive lectures (3.26). Due to the target group of learners, one can appreciate the emphasis on sharing and exchanging experience, especially through discussions, but even on the relatively often used tailored preparative activating methods, such as simulation (3.22), role-play (3.02), and case studies (3.19).

The analysis revealed that there are significant differences between the frequency of the usage of the individual methods; $F(13.6663)=19.18 ; p<0.001$. However, the post-hoc tests showed specific differences between the individual methods (see the graph of the average frequency of the usage of the individual methods, line segments designate the standard error mean).

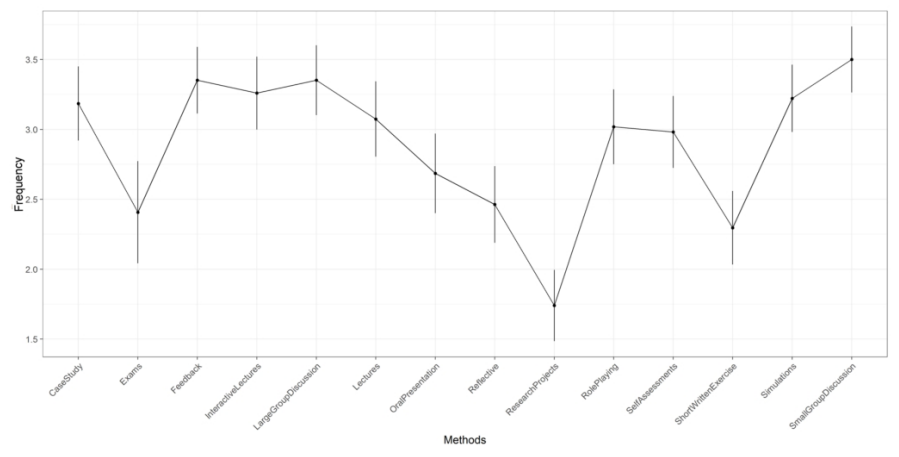

Figure 1: Average frequency of the usage of the individual methods (source: own research)

The further development of the effective use of the teaching methods can be undertaken in the field of so-called reflective methods that can, especially for managers with a lot of experience, significantly contribute to their further development as leaders. This is also supported by remembering to give feedback on activities carried out during full-time study as well as on homework assignments. 
The usefulness of the methods for the conceptual understanding of leadership

Respondents were asked to evaluate the usefulness of the specific teaching methods for the conceptual understanding of leadership. They were provided with a five-level scale (from $1=$ useless to $5=$ very useful). See Table 2 for the results.

The respondents of our research have designated the so-called experience-based methods as the most useful for their conceptual understanding of leadership. These are, especially, feedback (4.52), simulations and model situations (4.50), small group discussion (4.33) and case studies (4.33). Short written exercises (2.94) and exams and knowledge tests (2.67) were seen as least useful for their conceptual understanding of leadership.

\begin{tabular}{|l|c|c|}
\hline \multicolumn{1}{|c|}{ Method } & Mean & SD \\
\hline Feedback & 4.52 & 0.72 \\
\hline Simulations, Model Situations & 4.50 & 0.67 \\
\hline Small Group Discussion & 4.33 & 0.80 \\
\hline Case studies & 4.33 & 0.75 \\
\hline Role-Playing & 4.19 & 0.95 \\
\hline Interactive Lectures & 4.11 & 0.82 \\
\hline Oral Presentation & 4.07 & 0.87 \\
\hline Large Group Discussion & 3.96 & 0.89 \\
\hline Self-Assessment Questionnaires & 3.80 & 0.96 \\
\hline Reflective methods & 3.76 & 1.10 \\
\hline Lectures & 3.59 & 1.11 \\
\hline Research Projects & 3.07 & 1.18 \\
\hline Short Written Exercise & 2.94 & 1.11 \\
\hline Exams, Knowledge Test & 2.67 & 1.21 \\
\hline
\end{tabular}

Table 2: The usefulness of the teaching methods for the conceptual understanding of leadership, 2015 (source: own research)

Small group discussion (4.33) and oral presentation (4.07) seem to be useful for the conceptual understanding of leadership, i.e. methods that include sharing experience, but also interactive lectures (4.11), which fittingly combine the instructor's contribution with a discussion and the experience and opinions of students and case studies (4.33)

Research projects (3.07), seldom used in this type of study programme, can be judged as useful. In contrast, the least useful according to the respondents are the methods from the group exams and knowledge testing.

There are significant differences among the represented methods in the assessment of their usefulness for the conceptual understanding of leadership $(F(13.689)=27.08 ; p<0.001)$. Posthoc tests revealed specific differences between the individual methods (see the graph below, line segments designate the standard error mean).

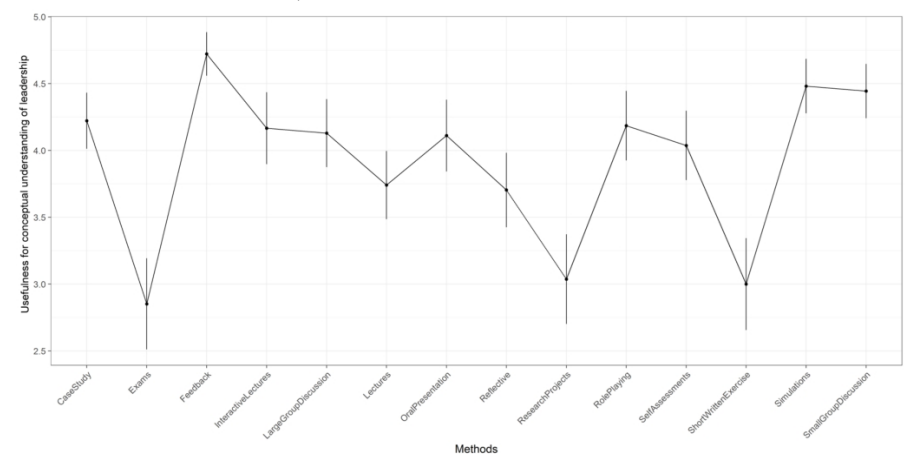

Figure 2: Average usefulness of teaching methods for the conceptual understanding of leadership (source: own research)

If we carry out a two-way analysis, it reveals that the individual methods are assessed differently with respect to their frequency of usage and influence on the conceptual understanding of leadership $(F(13.689)=5.89 ; p<0.001)$. The next graph shows the comparison of the frequency of usage of the given methods and the usefulness of these teaching methods for the conceptual understanding of leadership. It's obvious that the higher frequency of usage of methods such as Oral Presentations $(p<0.001)$, Reflective Methods $(p<0.001)$, Research Projects $(p<0.000)$, Role-Playing $(p<0.033)$, and Simulations $(p=0.015)$ could lead to the development of the conceptual understanding of leadership (see below).

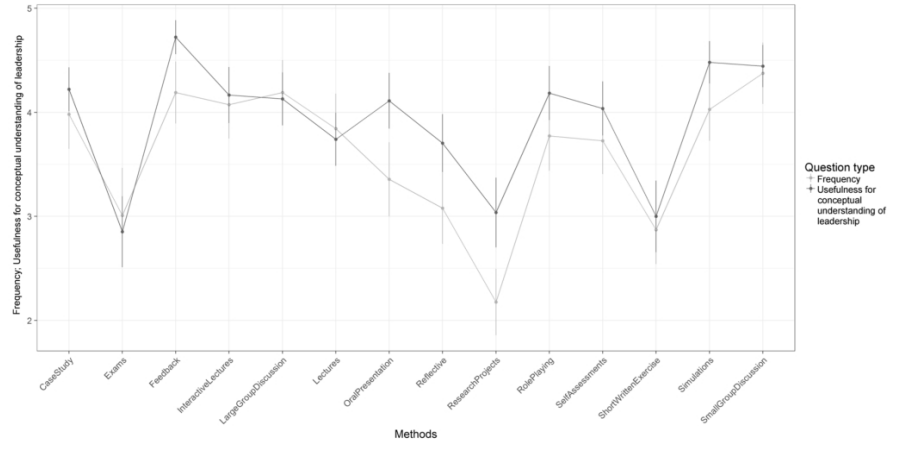

Figure 3: Comparing the frequency of usage of the methods and their usefulness for the conceptual understanding of leadership (source: own research)

\section{The usefulness of the methods for leadership skills development}

Respondents were asked to evaluate the usefulness of the teaching methods for leadership skills development. They were provided with a five-level scale (from $1=$ useless to $5=$ very useful). See Table 3 for the results.

In terms of leadership skills development, the respondents of our research found feedback (4.71), simulations, model situations (4.46), and small group discussion (4.42) most useful. Research projects (3.00), short written exercise (2.94) and exams, knowledge tests (2.79) were seen as least useful for leadership skills development.

\begin{tabular}{|l|c|c|}
\hline \multicolumn{1}{|c|}{ Method } & Mean & SD \\
\hline Feedback & 4.71 & 0.61 \\
\hline Simulations, Model Situations & 4.46 & 0.75 \\
\hline Small Group Discussion & 4.42 & 0.75 \\
\hline Role Playing & 4.27 & 0.77 \\
\hline Interactive Lectures & 4.25 & 0.81 \\
\hline Case studies & 4.21 & 0.78 \\
\hline Large Group Discussion & 4.10 & 0.93 \\
\hline Oral Presentation & 4.08 & 0.99 \\
\hline Self-Assessment Questionnaires & 4.06 & 0.96 \\
\hline Lectures & 3.71 & 0.94 \\
\hline Reflective methods & 3.71 & 1.04 \\
\hline Research Projects & 3.00 & 1.22 \\
\hline Short Written Exercise & 2.94 & 1.24 \\
\hline Exams, knowledge test & 2.79 & 1.23 \\
\hline
\end{tabular}

Table 3: The usefulness of the teaching methods for leadership skills development, 2015 (source: own research)

There are significant differences among the represented methods in the assessment of usefulness for leadership skills development $(p<0.00001)$. The analysis also revealed significant differences in the assessment of the usefulness of the teaching methods for 
leadership skills development $(F(13.689)=27.85 ; p<0.001)$. Post-hoc tests showed specific differences between the individual methods (see the graph below, line segments designate the standard error mean).

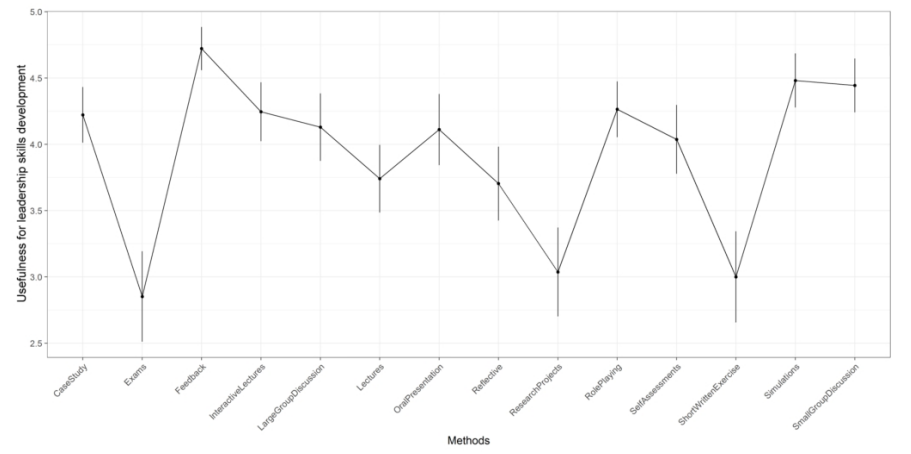

Figure 4: Average usefulness of the methods for leadership skills development (source: own research)

If we carry out a two-way analysis, it reveals that the individual methods are assessed differently in terms of their frequency of usage and influence on skills development $(F(13.663)=4.82$; $p<0.001)$. The next graph shows how the frequency of the usage of the individual methods differs from the usefulness of the methods for leadership skills development. The results indicate that increasing the frequency of the usage of certain methods (for example Feedback $(p=0.004)$, Oral Presentation $(p<0.001)$, Reflective Methods $(p=0.002)$, Research Projects $(p<0.000)$, Role-Playing $(p=0.014)$ and Simulations $(p=0.028)$ etc.) could have an influence on the perception of the usefulness of the methods for skills development.

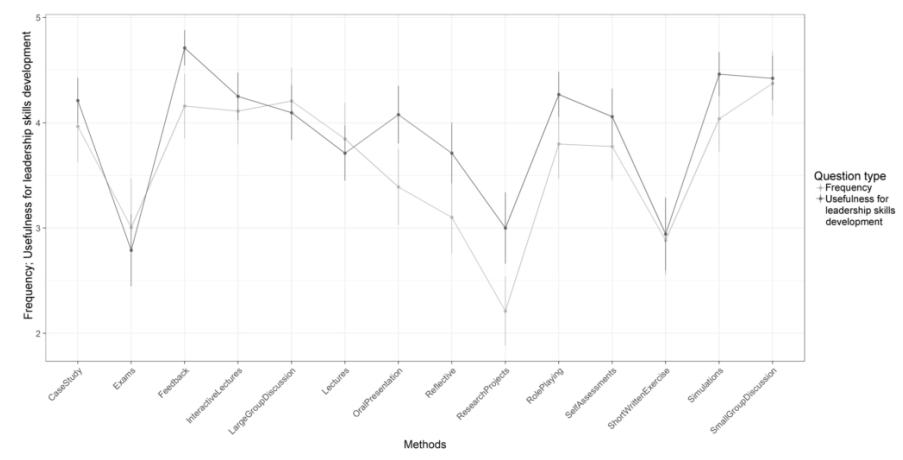

Figure 5: Comparing the frequency of the usage of the methods and their usefulness for leadership skills development (source: own research)

Knowledge level is an important basis for the further development of managers, but the focal point of the instruction is gradually shifting to the level of skills. It's not enough just to "know" or "memorize," but it's also necessary to know how to use and apply, i.e. acquire a wide spectrum of skills (social, managerial, and others). For example, the concept of versatile leadership (Pavlica, Jarošová and Kaiser, 2015) places an emphasis on managers' need to adopt various different, even contradictory, but mutually complementary skills together with versatile, wide-ranging application in practice.

\section{The usefulness of the methods for personal growth}

Respondents were asked to evaluate the usefulness of the particular methods for their personal growth. They were provided with a five-level scale (from $1=$ useless to $5=$ very useful). See Table 4 for the results.

The respondents have found feedback (4.81), small group discussion (4.45), simulations and model situations (4.40), and role-playing (4.34) most useful for their personal growth and self-knowledge. In contrast, they considered lectures (3.53), short written exercise (2.96), research projects (2.94), and exams and knowledge test (2.87) to be the least useful.

\begin{tabular}{|l|c|c|}
\hline \multicolumn{1}{|c|}{ Method } & Mean & SD \\
\hline Feedback & 4.81 & 0.39 \\
\hline Small Group Discussion & 4.45 & 0.67 \\
\hline Simulations, Model Situations & 4.40 & 0.78 \\
\hline Role Playing & 4.34 & 0.92 \\
\hline Self-Assessment Questionnaires & 4.22 & 0.99 \\
\hline Case studies & 4.09 & 1.00 \\
\hline Interactive Lectures & 4.04 & 1.02 \\
\hline Oral Presentation & 4.04 & 1.02 \\
\hline Large Group Discussion & 4.09 & 0.95 \\
\hline Reflective methods & 3.81 & 1.19 \\
\hline Lectures & 3.53 & 1.10 \\
\hline Short Written Exercise & 2.96 & 1.20 \\
\hline Research Projects & 2.94 & 1.17 \\
\hline Exams, Knowledge Test & 2.87 & 1.23 \\
\hline
\end{tabular}

Table 4: The usefulness of the teaching methods for personal growth, 2015 (source: own research)

The analysis also revealed significant differences in the perception of the usefulness of teaching methods for personal growth $(F(13.686)=27.10 ; p<0.001)$. Post-hoc tests showed specific differences between the individual methods (see the graph below, line segments designate the standard error mean).

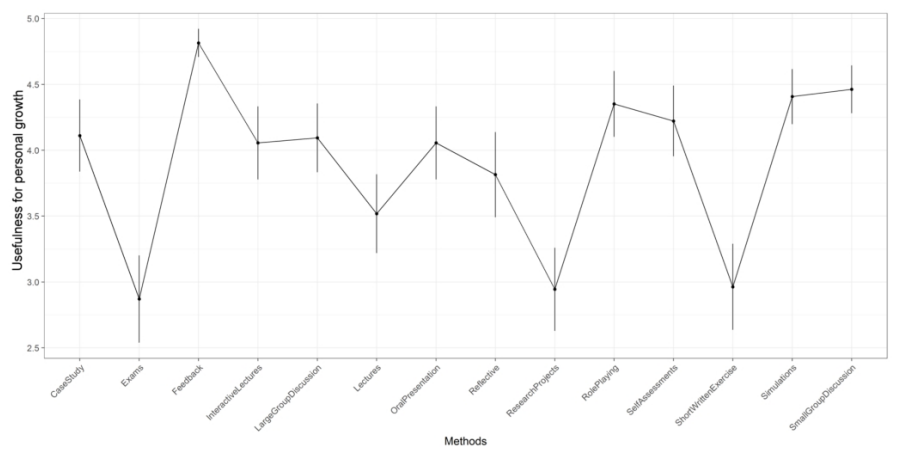

Figure 6: Average usefulness of the teaching methods for personal development (source: own research)

A two-way analysis reveals that the individual methods are assessed differently in terms of their frequency of usage and influence on personal growth $(F(13.667)=4.98 ; p<0.001)$. The next graph shows how the frequency of the usage of the individual methods differs from the usefulness of the methods for personal growth. Especially Feedback $(p=0.003)$, Oral Presentation $(p=0.001)$, Reflective Methods $(p<0.001)$, Research Projects $(p<0.001)$, Role-Playing $(p=0.007)$ and Self-Assessments $(p<0.019)$ are among the methods that could stimulate participants' personal growth if they were used in teaching more often.

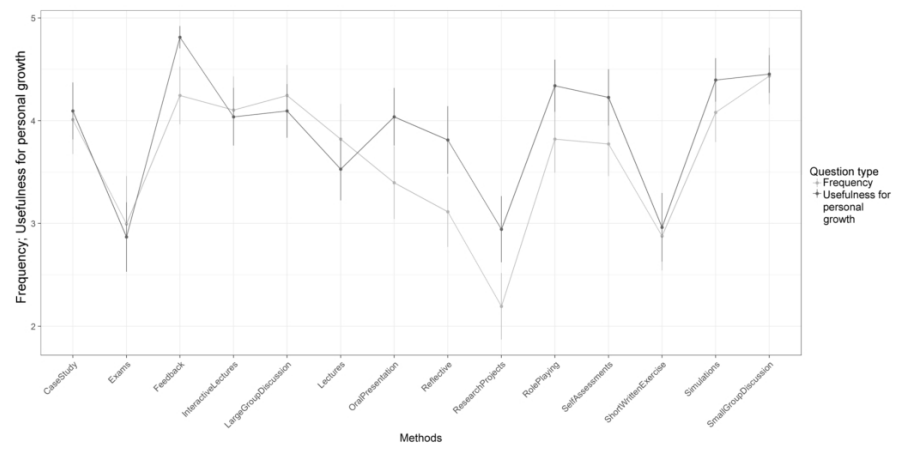

Figure 7: Comparison of the frequency of the usage of the methods and their usefulness for personal growth (source: own research) 
Self-knowledge is understood as the cornerstone of leadership as well as of the further development of managerial skills. It also entails knowledge of one's own typical behaviour patterns, and also awareness of one's strengths and weaknesses (Pavlica, Jarošová and Kaiser, 2015).

One must deepen one's self-knowledge and so-called selfacceptance in order to continue one's personal development, and getting to know and understand others (Rogers, 1961 in Pavlica, Jarošová and Kaiser, 2015).

\section{Discussion}

The limitations of this study may be perceived in the fact that the respondents of the survey were MBA and lifelong learning programmes participants who all come from the same educational institution, so the results can't be seen as representative. Also, only the participants, and not the course instructors, were asked to fill in the survey. However, as the methods used in the research were based on prior research studies from abroad, it is possible to discuss the results in their context. The studies mentioned are those of Allen and Hartmann (2009) and Jenkins (2013). Both are inspired (as is our study) by Conger's primary approaches to leadership development (personal growth, conceptual understanding, skill building and feedback), which were combined with different sources of learning commonly found in leadership development activities.

In the Allen and Hartmann study, the respondents were undergraduates who were asked to share their opinion on the way in which they would like to learn about leadership. The students showed a preference for developmental activities where the primary learning objective was individual personal growth and skill building. Jenkins's study brings an overview of leadership programmes from the perspective of educators. Three hundred and three leadership instructors from the USA, teaching inclass academic credit-bearing undergraduate leadership courses, were asked to participate. The instructors showed a preference for instructional strategies that emphasise class discussion, forms of conceptual understanding, and personal growth. On the other hand, they seldom used skill-building instructional strategies or traditional assessment. These results indicate that even leadership educators, though they pay less attention to skill development, lend a significance to in-class interaction and communication in leadership development programmes and do not overestimate traditional ways of assessment, such as tests.

Since our research study was focused on analysing the methods used in specific educational programmes, we concentrated on those that were relevant to them. Therefore we chose Jenkins's overview of teaching methods (Jenkins, 2013) as the basis for our survey. The research study thus didn't strive to provide a complete summary of teaching methods and approaches that can be used in educational programmes for managers. Other methods that are appropriate for programmes that develop leadership competencies were described and analysed by quite a few authors. Inspirational examples include peer-led team learning, in which specific problem-solving workshops comprised of small groups of students led by a specially trained peer leader (Dobson, Frye and Mantena, 2013) are included in the MBA programme, or the "live-case" intervention method, which consists of a CEO bringing to the classroom a strategic issue that he/she is currently struggling with to be discussed with students in real time (Rashford and De Figueiredo, 2010). The authors cited, like others (for example De Dea Roglio and Light, 2009) emphasised the significance of teaching methods for leaders' development that enable participants to actively participate in the learning process, but also reflect their current work and experience.

Similar conclusions can also be inferred from our research study. The statistical analysis showed a significant correspondence in the differences between the frequency of the teaching methods and their perceived usefulness for various purposes (conceptual understanding of leadership, leadership skills development, and personal growth). The results reveal the respondents' increased need to present their thoughts, opinions, and experiences (individually and in a team) orally in class. Reflective methods, research projects, role-playing, and simulations are other methods that should be used much more than they have been in the programmes assessed. In the case of leadership skills development and personal growth, the greatest difference between frequency and perceived usefulness was found in the feedback provided by a teacher or other class participants. If we consider that feedback is used rather often in the programmes assessed (see Table 1), it seems apparent that the participants consider the possibility of getting feedback as the greatest stimulus for the development of leadership competencies.

\section{Conclusion}

The results of the survey have confirmed the trends in education introduced in the introduction of this article, especially the limitation of traditional "teacher-oriented" teaching, and strengthening the use of modern "learner-oriented" teaching methods. Managerial education should entail, among other things, the development of its participants' leadership competencies.

The respondents of the research - MBA and lifelong learning programmes' students at the University of Economics, Prague - have found the methods that keep them active over the course of the training and enable them to develop their understanding of leadership concepts, skill development, and personal growth through getting feedback, sharing experiences and discussion, solving various problem situations through role play and simulations or case studies to be among the most useful. The results also suggest that respondents appreciate it the most if activities that, once completed, are followed by feedback from the instructor or other participants are included. The findings are also supported by the comparison of the frequency of the usage of the given methods and their perceived usefulness. It was shown that the participants of the assessed programmes would prefer that most of the teaching methods (especially the interactive ones) would be used more often, except for lectures and exams (in the case of personal growth even interactive lectures), where the frequency of usage was higher than their perceived usefulness. In this case, it leads to reflections on the best way that the managerial education programmes impart information and knowledge or to a question whether they should use other methods of assessment (for example research projects). The results of the study have practical implications for similarly specialised educational programmes. We can recommend that instructors consider a wide range of teaching methods to meet the various purposes in leadership development while designing managerial training programmes. While they are teaching, they must bear in mind the stock that the participants place in the possibility of getting feedback for their individual inputs in the teaching process through active teaching methods. Using these teaching methods places an emphasis on creating the right atmosphere in the group to support the active participation of all education programme participants, as well as providing and accepting feedback. 
The use of modern "learner-oriented" teaching methods places greater demands on the instructor, the level of his or her preparation, the ability to adapt the content and type of activities directly to the target group, and to plan time. Meeting these demands isn't easy. If managerial education programme instructors don't have the proper training in relevant pedagogical competencies, don't work on their further development, or don't get professional feedback about their teaching, their adequate usage of the teaching methods is highly unlikely.

\section{Acknowledgements}

This article was supported by the Norway Grants under the grant Creation of Teaching Methods in Lifelong Learning Programmes, number NF-CZ07-ICP-1-0302014.

\section{References}

Allen, S. J., and Hartman, N. S. (2009) 'Sources of learning in student leadership development programming', Journal of Leadership Studies, Vol. 3, No. 3, pp. 6-16. http://dx.doi. org/10.1002/jls.20119

Bedrnová, E., Jarošová, E. and Nový, I. (2012) Manažerská psychologie a sociologie, Praha: Management Press.

Beevers, K. and Rea A. (2010) Learning and Development Practice, London: Chartered Institute of Personnel and Development.

Bukve, O., Jarošová, E., Lorencová, H., Halvorsen, K., Půbalová, K. and Netteland, G. (2015) 'Teaching methods and learning strategies in lifelong learning programs,' 2015 EGPA Annual Conference - Conference Proceedings, EGPA, Toulouse.

Conger, J. (1992) Learning to Lead: The Art of Transforming Managers into Leaders. San Francisco, CA: Jossey-Bass.

Day, D. V. and Dragoni, L (2015) 'Leadership Development: An Outcome-Oriented Review Based on Time and Levels of Analyses', Annual Review of Organizational Psychology and Organizational Behavior, Vol. 2, pp. 133 -156. http://dx.doi. org/10.1146/annurev-orgpsych-032414-111328

De Déa Roglio, K., and Light, G. (2009). 'Executive MBA Programs: The Development of the Reflective Executive', Academy of Management Learning \& Education, Vol. 8, No. 2, pp. 156-173. doi:10.5465/AMLE.2009.41788840

Dobson, G., Frye, R., and Mantena, R. (2013). 'Leadership Training in an MBA Program Using Peer-Led Team Learning'. American Journal of Business Education, Vol. 6, No. 2, pp. $177-$ 190.

Hogan, R. and Kaiser, B. (2005). 'What we know about leadership', Review of General Psychology, Vol. 9, No. 2, pp. 169-180. http://dx.doi.org/10.1037/1089-2680.9.2.169

Hoover, J. D., Giambatista, R.C., Sorenson, R.L. and Bommer, W.H. (2010) 'Assessing the effectiveness of whole person learning pedagogy in skill acquisition', Academy of Management Learning and Education, Vol. 3, No. 2, pp. 192-203. http:// dx.doi.org/10.5465/AMLE.2010.51428543

Hall, D. T. (2004). 'Self awareness identity and leader development'. In Day, D. V., Zaccaro, J. S. and Halpin, M. (Eds.). Leader Development for Transforming Organizations: Growing Leaders for Tomorrow, pp. 153-170. Mahwah, NJ: Lawrence Erlbaum Associates.

Huba, M. E. and Freed, J. E. (2000) Learner-Centred Assessment on College Campuses: Shifting the Focus from Teaching to Learning, Needham Heights, MA: Allyn \& Bacon.

Jarošová, E., Lorencová, H., Půbalová, K. (2016) 'Efficiency and relevance of teaching methods in managerial education', Proceedings of the 13th International Conference Efficiency and Responsibility in Education, CZU, Prague.
Jenkins, D. M. (2013) 'Exploring Instructional Strategies in Student Leadership Development Programming,' Journal of Leadership Studies, Vol. 6, No. 4, pp. 48-62. http://dx.doi. org/10.1002/jls.21266

Knowles, M., S. (1980) The Modern Practice of Adult Education: From Pedagogy to Andragogy, Chicago: Follett.

Kotter, J. P. (1996) Leading Change, Boston: Harvard Business School Press.

Mehdinezhad V. and Sardarzahi Z. (2015) 'A Study of the Leadership Behaviors Reported by Principals and Observed by Teachers and its Relation with Principals Management Experience" Journal on Efficiency and Responsibility in Education and Science, Vol. 8, No. 2, pp. 48-53. http://dx.doi. org/10.7160/eriesj.2015.080203

Pavlica, K., Jarošová, E. and Kaiser, R, B. (2015) Vyvážený leadership. Dynamika manažerských dovedností, Praha: Management Press.

Rashford, N. S., and De Figueiredo, J. N. (2010). 'The "Live-Case" Intervention Method: Leadership Skills Through Experiential Learning'. Academy of Management Annual Meeting Proceedings, Vol. 1, pp. 1-6. doi:10.5465/ AMBPP.2010.54484414

Sadler-Smith, E. (2006) Learning and Development for Managers: Perspectives from Research and Practice, Malden, MA: Blackwell Publishing.

Waddock, S. and Lozano, J. M. (2013) 'Developing more holistic management education: Lessons learned from two programs', Academy of Management Learning and Education, Vol. 12, No. 2, pp. 265-284. http://dx.doi.org/10.5465/amle.2012.0002 